\title{
The Other Side of the (Policy) Coin: Analyzing Exnovation Policies for the Urban Mobility Transition in Eight Cities around the Globe
}

\author{
Lisa Graaf 1,2,*, Stefan Werland ${ }^{2, *}$, Oliver Lah 1,2,3 ${ }^{\mathbb{D}}$, Emilie Martin ${ }^{3}$, Alvin Mejia ${ }^{2}$, María Rosa Muñoz Barriga ${ }^{2}$, \\ Hien Thi Thu Nguyen ${ }^{4}$, Edmund Teko ${ }^{3}$ and Shritu Shrestha ${ }^{2}$
}

1 Habitat Unit, Technische Universität Berlin (TU Berlin), 10623 Berlin, Germany; oliver.lah@wupperinst.org or oliver.lah@tu-berlin.de

2 Wuppertal Institute for Climate, Environment, Energy, 42103 Wuppertal, Germany; alvin.mejia@wupperinst.org (A.M.); maria.munoz@wupperinst.org (M.R.M.B.); shritu.shrestha@wupperinst.org (S.S.)

3 Urban Electric Mobility Initiative (UEMI), 10437 Berlin, Germany; emilie.martin@uemi.net (E.M.); edmund.teko@uemi.net (E.T.)

4 Department of Science, Technology and International Cooperation, University of Transport Technology (UTT), Hanoi 100000, Vietnam; hienntt@utt.edu.vn

* Correspondence: lisa.graaf@wupperinst.org (L.G.); stefan.werland@wupperinst.org (S.W.)

Citation: Graaf, L.; Werland, S.; Lah, O.; Martin, E.; Mejia, A.; Muñoz Barriga, M.R.; Nguyen, H.T.T.; Teko, E.; Shrestha, S. The Other Side of the (Policy) Coin: Analyzing Exnovation Policies for the Urban Mobility Transition in Eight Cities around the Globe. Sustainability 2021, 13, 9045. https://doi.org/10.3390/su13169045

Academic Editors: Anna Martius, Peter D. Lund, Lutz Hagen and Jörn Schönberger

Received: 18 June 2021

Accepted: 10 August 2021

Published: 12 August 2021

Publisher's Note: MDPI stays neutral with regard to jurisdictional claims in published maps and institutional affiliations.

Copyright: (c) 2021 by the authors. Licensee MDPI, Basel, Switzerland. This article is an open access article distributed under the terms and conditions of the Creative Commons Attribution (CC BY) license (https:// creativecommons.org/licenses/by/ $4.0 /)$.

\begin{abstract}
Many cities all over the world highlight the need to transform their urban mobility systems into more sustainable ones, to confront pressing issues such as air and noise pollution, and to deliver on climate change mitigation action. While the support of innovations is high on the agenda of both national and local authorities, consciously phasing-out unsustainable technologies and practices is often neglected. However, this other side of the policy coin, 'exnovation', is a crucial element for the mobility transition. We developed a framework to facilitate a more comprehensive assessment of urban mobility transition policies, systematically integrating exnovation policies. It links exnovation functions as identified in transition studies with insights from urban mobility studies and empirical findings from eight city case studies around the world. The findings suggest that most cities use some kinds of exnovation policies to address selective urban mobility issues, e.g., phasing-out diesel buses, restricting the use of polluting motor vehicles in some parts of the city, etc. Still, we found no evidence for a systematic exnovation approach alongside the innovation policies. Our framework specifies exnovation functions for the urban mobility transition by lining out policy levers and concrete measure examples. We hope that the framework inspires future in-depth research, but also political action to advance the urban mobility transition.
\end{abstract}

Keywords: urban sustainable mobility; transition; innovative mobility concepts; socio-technical regimes; exnovation

\section{Introduction}

Cities all over the world are struggling to transform their mobility systems in order to reduce congestion, noise and air pollution, and transport related $\mathrm{CO}_{2}$-emissions. The push for a renewal of urban mobility systems stems from various sources, both from within and from outside the existing mobility system. Pressure from inside the dominant 'system of automobility' results from its own self-expansion [1]: the rapid motorization of cities is pushing infrastructures to their limits, worsening urban congestion, increasing travel time, and leading to a growing number of road accidents. Attempts to deal with growing motorized individual transport often build on a predict-and-provide approach that extrapolates past developments and derives assumptions about the 'adequate' size of future transport infrastructure [2]. An increasing number of city administrations, however, realize that the 'usual' strategy of ever increasing road capacity may ease the situation in 
the short term, but leads to more car traffic and ultimately worsens the situation in the mid- to long-term [3]. Pressure from outside the dominant, car-centered urban mobility regime (following Geels's Multi-Level Perspective: the 'landscape' level; [4,5]) comes from a variety of directions: An ever increasing number of cities have adopted climate strategies and actions plans, or sustainable development strategies, which comprise sector targets for mobility. Other landscape factors are human health issues linked to transport-related air and noise pollution, as reflected in EU environmental legislation for example [6,7]. Moreover, in ever more cities, civil society grassroot organizations have been emerging over the last years, demanding a reallocation of scarce urban space and a curbing of motorized individual transport in the inner cities. Finally, a modern and low carbon transport system can support a city brand as a smart city or sustainable city and, thus, be an asset in the global competition for attracting future companies and highly skilled workers [8].

Transition studies: Following the transition studies perspective $[9,10]$, urban mobility systems can be understood as socio-technical regimes: configurations of different elements, including technologies and products, infrastructures, social norms and values, behavioral patterns, markets, knowledge, production, regulation, and political institutions. These elements are interlinked, locking-in the current equilibrium of the system that favors motorized individual transport [11]. As a consequence, the mere provision of protected niches and incentives to support sustainable mobility innovations will not suffice to achieve a profound transition of urban mobility systems. It is also essential to exert pressure on the existing dominant regime and to consciously phase-out non-sustainable regime elements.

This exnovation-side of transition processes is often neglected. Targeted destabilization of system elements is a precondition for overcoming locked-in unsustainable urban mobility systems. Kungl and Geels [12] stress that if policymakers are serious about limiting climate change to $1.5^{\circ} \mathrm{C}$, they will have to complement low-carbon innovation policies with active phase-out and dis-continuation policies. Agarwal et al. argue that " ... while the increasing emphasis on public transport has seen wide acceptability [ ... ], the complementary effort of restraining the demand for personal motor vehicles by making users pay the full price of ownership and operation has only seen limited application" [3]. As stressed by the Fifth IPCC Assessment Report, the decarbonization of the transport sector will only be feasible if all available measures to avoid unnecessary travel, shift towards low-carbon modes, and improve the efficiency and carbon intensity of vehicles and energy carriers are synchronized and well-integrated [13]. Hence, both innovation towards new vehicle and service concepts are equally important as measures to phase-out carbon-intense forms of transportation, which are considered to be 'exnovations' in this paper.

The term 'exnovation' was described already 40 years ago in the context of organizational planning (ending obsolete bureaucratic practices; [14]) and is frequently used in medical studies (replacing old equipment; [15-17]). While the destabilization of existing regimes in general plays an important role in transition studies (e.g., $[18,19])$, transition scholars only recently started to focus more on this side of the (policy) coin, especially with a view to the energy transition. Scientists emphasize that lock-in effects from the existing system configuration hamper the diffusion of innovative solutions. Those obstacles include higher costs compared to "conventional" products due to necessary upfront investments, lack of economies of scale, or still missing learning curves; the need to overcome behavioral routines; or infrastructures and regulations that are tailored to the needs of the dominant technologies [19-24].

Exnovation measures, aiming at destabilizing non-sustainable regimes by reconfiguring critical system elements, should—following Kivimaa and Kern [25]—(1) introduce control policies for the 'old regime' (e.g., via bans, taxes), (2) strengthen significant changes in regime rules (e.g., via new overarching laws, changed policy priorities), (3) reduce support for dominant regime technologies (e.g., via removal of subsidies and R\&D funding), and (4) institutionalize changes in social networks and replace key actors (e.g., creation of new committees with niche actors). While the re-allocation of material resources is 
obviously an important aspect, altering the access to non-material resources like political influence, and social norms and values need also to be considered as essential levers for policy interventions. This is because the cultural significance attached to a specific regime also forms the selection environment [26], determining which solutions are politically viable, and helping to stabilize a certain discourse coalition or the status quo of a sociotechnical regime, respectively. Therefore, narratives and stories have increasingly gained prominence in energy and climate change research (for a summary see [27]; also [28,29]).

Kungl and Geels [12] highlight the importance of sequence and alignment of external pressures in destabilization processes in socio-political and economic contexts, like e.g., negative discourse, divestment, reduced demand. Along those same lines, David and Gross [30] link exnovation with the notion of real-world experimentation. They argue for trial processes of exnovation, to show how exnovation can be successfully articulated once sustainability becomes a strong narrative of an envisioned future and how policymakers might respond (ibid). Further policy recommendations regarding exnovation processes are to set clear phase-out targets, to start early, but rather long-term processes [12,22] and to form broad coalitions with different actors to legitimize phase-out measures [22]. Moreover, socio-economic consequences for the workforce or entire regions should be alleviated with special policy instruments, easing adaptation [12,23].

Mobility Studies: A concept that is related to the innovation/exnovation approach in the mobility sector is the distinction between 'push measures' that discourage private car use and 'pull measures' that provide more sustainable alternatives [31]. This concept provides a useful starting point for the analysis of policy interventions, though it focuses on individual measures and not on entire regimes. In his analysis of the transport system in the United Kingdom and the Netherlands, Geels [32] (p. 480) concludes that policy makers are reluctant to introduce anti-car regulations because they are dependent on both the car industry and on their electorate, who may see restraints on private car use as an interference with their freedom. A survey among ca. 30 representatives of European cities, which had been conducted in the H2020 'SPROUT' project, confirmed this general tendency towards the implementation of innovation or pull measures [33]. Participants were asked to select those policy interventions that they have already implemented from a long list of ca. 100 push and pull measures. Although the number of participants was too small to draw generally valid conclusions, the survey results still provide a first orientation on the use of urban mobility measures: The survey results showed that innovation instruments such as the procurement of e-buses or the expansion of bicycle networks were used much more frequently than measures that increase the cost of or restrict private car use. Exceptions were parking management and the establishment of pedestrian zones, both of which 60 percent of the cities had implemented. Half of the cities had implemented $30 \mathrm{~km} / \mathrm{h}$ streets. Less than half of them had redistributed public space at the expense of cars, or introduced traffic calmed areas. About one third had pedestrianized areas, re-allocated car lanes to bikes and public transport, reduced the number of on-street car parking spaces, or restricted the access to the city center for private vehicles. A total ban of combustion vehicles from the city center, congestion charges, or other pricing systems for vehicle access (e.g., by emission category) were used in few cities only. Respondents were also asked to evaluate the political feasibility of the individual measures. The survey found that city representatives considered push measures, i.e., the discontinuation of privileges, generally less politically viable than the provision and funding of alternatives for private motorized transport.

Urban mobility systems: The appropriate scope of the mobility transition is still a matter of dispute both among the broad range of stakeholders and in the literature (e.g., [34]). For example, whether the electrification of private cars already counts as a fundamental change of the mobility system or whether it is a mere incremental technical development, is debated. Following the socio-technical system approach, scholars argue that a reconfiguration of the 'car-dependent transport system' (e.g., [1,11,35], and overcoming the "automobile urbanism" [36], (p. 7) requires more encompassing adjustments. 
The following list is a compilation of regime components that perpetuate the car-centered mobility system and which are (co-)defined on the city level [37,38]:

- technologies and products, such as vehicles and propulsion technologies, including cars, vans, buses, trucks, trains and rolling stock, urban rails, IT solutions for navigation and public transport apps;

- infrastructures and allocation patterns of urban space among those components; including car, bus, and bike lanes, parking spaces, sidewalks, pedestrian areas; or petrol and charging stations. Infrastructures are long-lasting assets and define the physical configuration of the mobility system for decades;

- planning practices and car-oriented planning traditions that shape the physical urban structures and the allocation of public space;

- mobility habits, routines, and cost structures of mobility options;

- formal and informal institutions, including dedicated mobility planning departments and the influence of stakeholder groups on mobility-related decisions;

- social norms, shared values, and attitudes that define legitimate or desirable use streets and public space that are often codified in legal provisions and regulations that shape the allocation of urban space among the mobility modes.

Legal competencies and scopes of action differ from city to city, and some regime elements are beyond the influence of urban administrations (e.g., university curricula for urban planners, the macroeconomic relevance of car manufacturers, or fuel taxation).

We assume that individual mobility choices, i.e., whether a journey is made in a car, by bicycle, on foot, or with public transport or shared mobility services depends on individual utility functions, including the availability, convenience, and perceived safety of each service and the prices of transport modes [39,40]. It is important to note that these elements are interlinked in a relative logic: Cost of one transport mode (e.g., public transport tickets) is considered in relation to costs of other modes (e.g., parking fees); and in dense urban settings, where urban space is distributed in a pareto-efficient way, the extension of infrastructure for one mobility mode will be at the cost of other modes.

With this article, we intend to contribute to the systematic study of urban mobility transitions, adding a perspective that has so far been mostly neglected: how unsustainable technologies and practices can deliberately and actively be terminated (or exnovated) in order to free space for the diffusion and 'normalisation' of innovative technologies, business models, and behavior. Based on transition studies, we develop and detail a framework to assess exnovation policies. To this end, we explored the policies of eight cities worldwide, that actively promote different kinds of e-mobility solutions: Kigali (Rwanda), Dar es Salaam (Tanzania), Hanoi (Vietnam), Pasig (Philippines), Madrid (Spain), Hamburg (Germany), Kathmandu (Nepal), and Quito (Ecuador). Our main research interest is to find out whether these cities have introduced exnovation policies within the past couple of years (research question 1), and if yes, which exnovation measures and mechanisms are most commonly used (research question 2), and whether the cities follow a systematic and comprehensive approach-in contrast to only selectively targeting individual elements of the urban mobility system (research question 3).

With this study we want to gain insights on the state of urban exnovation policies and fill the gap-the innovation bias-in mobility studies, which aims to stress the need for complementarity of innovation and exnovation measures. We develop and test an assessment framework that builds upon transition studies, while adding insights from urban planning and mobility studies. The framework supports the strategic assessment of urban mobility transition policies by adding and detailing the exnovation perspective to the discussion, both for researchers and decision makers.

\section{Materials and Methods}

Our first step was to derive an assessment framework, which would allow us to systematically collect data across our case studies (see below). The second step was to complete the assessment framework for each city via desktop research. The individual 
researchers act as city focal points in the Horizon 2020 research project SOLUTIONSplus and are in close contact with practitioners on the ground. Additional sources were interviews with local stakeholders, including city administration staff, mobility practitioners, civil society organizations, or local researchers that were carried out in the context of the SOLUTIONSplus project and were used for validating the assessment. As a fourth step, we summarized our findings and drew first conclusions on the use of exnovation measures in eight cities around the globe.

We have limited the scope of our assessment to measures that have been introduced in the past 10 years. With this temporal scope we account for the exnovation perspective, which stems primarily from the fact that elements of the existing system need to be changed or ended in order to make room for more sustainable technologies and practices.

All case study-cities are actively pursuing an urban mobility innovation pathway, as they are currently implementing new e-mobility solutions under the EU-funded SOLUTIONSplus project. Due to the broad international scope, with cities in Asia, Africa, Latin America, and Europe, there are huge differences in the status quo of the current mobility systems. While cities in (post-)industrialized countries have high rates of car ownership and extensive car infrastructure, and, thus, face lock-in effects that stabilize unsustainable mobility systems, cities in the Global South-though they have comparatively higher modal shares for walking and collective transport modes-are also faced with increasing shares of private or for-hire motorized transport, including motorcycles. However, all cities share some fundamental problems, including congestion, air and noise pollution, safety issues especially for vulnerable road users, and a lack of space for human interaction and active mobility. Although the configuration of the systems and the respective system elements differ a lot, we believe that the systemic approach we chose can help shedding light on neglected aspects of mobility transformations, and, thus, to formulate further research needs and policy recommendations.

Our assessment framework consists of four exnovation functions (first column). The center column is policy instruments and measures. Policy instruments and measures are means to achieve the exnovation function.

Our assessment framework builds on Kivimaa and Kern's [25] (p. 208) policy framework for creative destruction, in which the authors complement the strengthening of innovations with four mechanisms of regime destabilization ('destruction function'), each covering a range of policy instruments. We adapted their framework to account for additional insights from transition literature, slightly renaming or summarizing the original four 'destabilizing functions'. Drawing from insights from transition literature, where changes in narratives and discourses shaping public opinion, the so-called landscape level, are important to allow innovations to evolve and spread into the mainstream $[12,18,27]$, we added a new exnovation function (E4) on the importance of eroding the legitimacy and the social acceptance of certain kinds of behavior as depicted in Table 1. Policy measures or instruments for this function include the development of experiments to show how exnovation can be successfully articulated, making alternatives tangible through (temporary) changes and-in the longer run-changing public perception and narratives [30]. In the last column, we refer to the original framework and/or additional sources. 
Table 1. Framework for assessing exnovation elements in the city case studies.

\begin{tabular}{|c|c|c|}
\hline Exnovation Function & Policy Instruments/Measures & $\begin{array}{c}\text { Source/ } \\
\text { Literature }\end{array}$ \\
\hline $\begin{array}{l}\text { E1: Bans on unsustainable } \\
\text { technologies and practices }\end{array}$ & $\begin{array}{l}\text { Regulation (1), like legally binding rules, provisions that } \\
\text { ban certain products and technologies and/or prohibit or } \\
\text { prescribe specific activities, behaviors, or procedures }\end{array}$ & $\begin{array}{l}\text { Kivimaa and } \\
\text { Kern } 2016 \text { ([25] based on } \\
\text { "Destruction function 1", } \\
\text { adapted) }\end{array}$ \\
\hline $\begin{array}{l}\text { E2: Significant } \\
\text { changes in regime } \\
\text { rules }\end{array}$ & $\begin{array}{l}\text { Financial instruments (2) } \\
\text { Measures that alter cost structures, e.g., phasing out of } \\
\text { subsidies and R\&D funding; measures to internalize } \\
\text { external costs; } \\
\text { Public procurement (3) } \\
\text { Using the purchasing power of public households: } \\
\text { excluding products and technologies from public tenders } \\
\text { Provision of strategies and planning approaches (4) } \\
\text { Policy documents that lay down sector-specific objectives } \\
\text { and targets and provide orientation for decision makers, } \\
\text { economic actors, and individuals } \\
\text { Provision and/or modification of non-binding standards } \\
\text { and technical guidelines (5) } \\
\text { Elaboration and provision of non-binding information to } \\
\text { support planning and procurement activities. }\end{array}$ & $\begin{array}{l}\text { Kivimaa and } \\
\text { Kern 2016 ([25], based on D2 } \\
\text { and D3, summarized and } \\
\text { adapted; instruments added) }\end{array}$ \\
\hline $\begin{array}{l}\text { E3: Change in the allocation of } \\
\text { institutional and material } \\
\text { resources }\end{array}$ & $\begin{array}{l}\text { Institutional changes (6) } \\
\text { that alter the influence and power of administrative } \\
\text { departments and other stakeholders who traditionally } \\
\text { support the 'old structures', e.g., creation of new } \\
\text { departments and administrative units or the creation of } \\
\text { powerful committees with involvement of niche actors. } \\
\text { Redistribution of material resources (7) } \\
\text { Changing the allocation of and access to physical resources. }\end{array}$ & $\begin{array}{c}\text { Kivimaa and } \\
\text { Kern } 2016 \text { ([25], D4 adapted) }\end{array}$ \\
\hline $\begin{array}{l}\text { E4: De-legitimising existing non } \\
\text { sustainable practices/routines } \\
\text { and technologies }\end{array}$ & $\begin{array}{c}\text { Information and PR campaigns (8) } \\
\text { targeting public opinion and emphasizing, e.g., the } \\
\text { climate/health/social impact of unsustainable practices } \\
\text { (e.g., CO2 footprints; energy labels) } \\
\text { Experimentation (9) } \\
\text { Making alternatives tangible through (temporary) } \\
\text { experiments }\end{array}$ & $\begin{array}{l}\text { new function compared to } \\
\text { Kivimaa and Kern; based on } \\
\text { Geels [18]; } \\
\text { David and Gross 2019 [30] }\end{array}$ \\
\hline
\end{tabular}

City researchers applied the generic exnovation assessment framework to the urban mobility system in their city. The assessment of exnovation functions was applied to the system elements. In order to keep this task manageable, we had grouped the system elements into four broader categories: products and technologies; mobility behavior and social values; planning practices and legal framework; and urban space and infrastructure. For each of them, city experts went through the policy categories 1-9. Empirical findings for all cities were then compiled and are presented in the following Chapter 3: Results.

For the assessment, we used a quantitative approach, i.e., counting of measures. We are aware that this approach misses the completeness of policy responses, the level of ambition, the rigor of the actual implementation, and the actual impact on the urban mobility system. Since we were interested in gaining a broader overview of potential measures, however, conducting qualitative assessments or even a ranking of city activities is not the aim of this article-though we hope to inspire future in-depth case studies that cover such aspects through this framework.

The scope of our paper is the city level and focuses on activities of urban administrations. Still, as national, and regional (i.e., European) legislation can either directly influence the urban mobility system, or facilitate local action, the city researchers also registered relevant national and regional level legislation, though in a less comprehensive way. Relevant 
findings on multi-level policies are presented in Chapter 4: Conclusions. During the data collection it became clear that the exnovation functions and measures categories are not always clear-cut and there is a certain degree of vagueness and overlapping. For example, the conversion of car lanes into cycle lanes, depending on the concrete formulation, might be considered as a kind of regulation (and, thus, belong under 'banning unsustainable practices', E1), or as a change in regime rules (this would be E2), but it might also be interpreted as a highly visible, official de-legitimation of 'unrestricted' car use on streets (therefore belonging in E4). Notwithstanding those ambiguities, which are inherent in most such frameworks, the approach proved to be a valuable tool for understanding different aspects of exnovation and served as the basis for the systematic and coherent assessment of policies in the individual cities.

\section{Results: Findings from the Case Studies \& Discussion}

We first summarize our findings regarding the planned or implemented exnovation measures in our case studies, and present them along the exnovation functions, before discussing the comprehensiveness of the approach (the elements of the mobility system).

\subsection{Exnovation Functions: Cities Exnovation Policies and Measures}

The results for clustering the measures and policy instruments into the exnovation functions is summarized in the following. The categories of policy instruments/measures (see Table 1) are highlighted in bold, the specific — mobility related-types of instruments and measures, which we found in the cities, are introduced in italic.

\subsubsection{Exnovation Functions 1: Bans of Unsustainable Technologies and Practices}

While emission standards and registration bans for vehicles are usually set on the national level, the case studies have shown that cities can ban or restrict the use of certain vehicles on their territory, mostly based on emission categories of age (see Table 2). Almost all cities have implemented different kinds of regulations (1) to ban unsustainable technologies and practices, albeit with a broad variety in terms of technological and spatial scope:

Table 2. Results of the case studies—exnovation function E1 "bans on unsustainable technologies and practices".

\begin{tabular}{|c|c|c|c|c|c|c|c|c|}
\hline & Ma & HH & Kig & Ha & Pas & Kat & Qui & Dar \\
\hline \multicolumn{9}{|c|}{ E1: Bans on Unsustainable Technologies and Practices } \\
\hline \multicolumn{9}{|c|}{ Regulation (1) } \\
\hline $\begin{array}{c}\text { Circulation bans/access restrictions based on } \\
\text { vehicle characteristics }\end{array}$ & $\mathrm{x}$ & $(\mathrm{x})$ & $(\mathrm{x})$ & $P$ & $\mathrm{x}$ & $(\mathrm{x})$ & $\mathrm{x}$ & \\
\hline $\begin{array}{c}\text { Ban/regulation of mobility services based on } \\
\text { vehicle characteristics }\end{array}$ & & & $(\mathrm{x})$ & & & $(\mathrm{x})$ & & $(\mathrm{x})$ \\
\hline Speed limits (beyond national limits) & $\mathrm{x}$ & & & & & & & \\
\hline
\end{tabular}

[x = adopted/implemented, $(\mathrm{x})=$ limited or small-scale implementation, $P=$ planned $]$.

Circulation bans or access restrictions for certain kinds of motorized vehicles in specific areas of the city, and so-called Low Emission Zones (LEZ) have been introduced rather recently in Madrid, Hamburg, Pasig, Quito, Kathmandu, and Kigali, or are planned to be introduced soon (as in Hanoi). The city-specific implementations, however, differ a lot in scope and ambition: in Quito and Hanoi a rather comprehensive transformation of the city center is planned. In Madrid, the ambitious and flag-ship LEZ in the city center was partially withdrawn after the change of government in 2019; however, the city will soon implement eight additional LEZ in the southern Municipios, comprising 1 Mio inhabitants. Kigali's strategy of a city-wide non-motorized transport (NMT) network was kicked-off in the 2013 Transportation Master Plan and reaffirmed in the 2020 planning documents. Hamburg, on the other hand, implemented a very selective and small-scale intervention. Responding 
to European air quality regulations, the city closed two road segments for elderly diesel vehicles.

Regulation of mobility services: Dar es Salaam banned motorcycles from operating as taxis in the city center not only because of their impacts on congestion and air pollution but primarily due to road safety concerns and alleged links to criminality [41,42]. Moreover, non-taxi users of motorcycles and three-wheelers who desire to enter or park in the Central Business District (CBD) of Dar es Salaam are expected to apply for a permit from the Dar es Salaam City Council before doing so [43]. Already in 1999, Kathmandu, based on a national government initiative, banned all diesel-run 3-wheelers for public transport and tried to replaced them with electric 3-wheelers (named Safa Tempos) in response to air pollution and as a consequence of the Indian trade embargo in 1989/1990, which impacted on Nepal's fuel supply [44,45]. Still, the remaining Safa Tempos are under pressure from fossil fueled micro buses, which were considered clean vehicles at the time and not affected by the ban [46].

Speed Limits: With the Sustainable Mobility Ordinance in 2018 [47], Madrid introduced a speed limit of $30 \mathrm{~km} / \mathrm{h}$ on single lane streets, affecting $80 \%$ of the total number of streets in the whole city, lowering the standard inner city speed limit of $50 \mathrm{~km} / \mathrm{h}$ in Spain. The speed limit was implemented to reduce the number of road accidents and encourage walking and cycling.

\subsubsection{Exnovation Function 2: Significant Changes in Regime Rules}

This exnovation function comprises rules that direct and coordinate the activities of mobility stakeholders. Related measures directly address the costs of mobility options, e.g., through pricing the use of vehicles, or alter framework conditions for a broader set of stakeholders. The latter inter alia includes public procurement provisions that influence product portfolios of vehicle manufacturers; city strategies and mobility planning paradigms, or technical handbooks and guidelines that define minimum standards for infrastructures (see Table 3).

Table 3. Results of the case studies-exnovation function E2 "significant changes in regime rules".

\begin{tabular}{|c|c|c|c|c|c|c|c|c|}
\hline & Ma & HH & Kig & Ha & Pas & Kat & Qui & Dar \\
\hline \multicolumn{9}{|c|}{ E2: Significant Changes in Regime Rules } \\
\hline \multicolumn{9}{|c|}{ Financial mechanism (2) } \\
\hline Pricing of on-street parking & $\mathrm{x}$ & $x$ & $\mathrm{x}$ & $\mathrm{x}$ & $\mathrm{x}$ & & $x$ & \\
\hline \multicolumn{9}{|c|}{ Public procurement (3) } \\
\hline $\begin{array}{l}\text { Exclusion of diesel public transport vehicles from } \\
\text { public tenders }\end{array}$ & $\mathrm{x}$ & $\mathrm{x}$ & & & & & $\mathrm{x}$ & \\
\hline \multicolumn{9}{|c|}{ Provision of strategies and modified planning approaches (4) } \\
\hline $\begin{array}{c}\text { City strategies and plans highlighting changed policy } \\
\text { priorities for urban mobility }\end{array}$ & $x$ & $\mathrm{x}$ & $\mathrm{x}$ & $P$ & $\mathrm{x}$ & & $\mathrm{x}$ & $\mathrm{x}$ \\
\hline $\begin{array}{c}\text { Standards for urban planning (TOD, compact, mixed } \\
\text { use, etc.) }\end{array}$ & & & $\mathrm{x}$ & & $\mathrm{x}$ & & $\mathrm{x}$ & $\mathrm{x}$ \\
\hline \multicolumn{9}{|c|}{ Provision and revision of standards and technical guidelines (5) } \\
\hline Quality standards for bike lanes & $(\mathrm{x})$ & $\mathrm{x}$ & $\mathrm{x}$ & & $x$ & $P$ & $(\mathrm{x})$ & \\
\hline $\begin{array}{l}\text { Building regulations (ending provisions on car } \\
\text { parking spaces) }\end{array}$ & & $x$ & $(\mathrm{x})$ & & $x$ & & $(\mathrm{x})$ & \\
\hline
\end{tabular}

[x = adopted/implemented, $(\mathrm{x})=$ limited or small-scale implementation, $P=$ planned $].$

Financial instruments (2) to discourage the use of private motorized vehicles are relatively widespread in the cities: While we found that costs of vehicle ownership are often determined on the national level via registration and vehicle taxes, urban authorities can influence the costs of using cars in the city. 
The most widespread example is the pricing of on-street parking, i.e., charging a fee for the private use of public space. Such schemes are implemented in Madrid, Hamburg, Kigali, Hanoi, Pasig, and Quito. Hamburg, for example, charges ca. 5 EUR per 2 h parking in the city center (compared to 3.40 EUR for the cheapest public transport ticket); Quito charges 0.40 Centavos (compared to 0.25 ctvs for a public transport ticket). Low parking fees have limited the efficiency of parking policies in Kigali so far; yet, this may change following the update of planning rules in 2020, recognizing the need to reduce parking demand and to "discourage private vehicle use" via correct pricing of on-street parking [48]. Fees for resident parking permits (which is in fact a cost of car ownership that is levied at the city level) are another lever for cities to influence mobility behavior. Hamburg issues permits that exempt holders from parking charges in their respective home neighborhoods. Still, a recently removed national regulation has restricted the maximum amount of the fee to costs of the administrative burden for issuing the badge-resulting in very low costs of $30 €$ per year in Hamburg.

Public procurement decisions (3) and incentives for vehicle manufacturers to phaseout unsustainable vehicles: Due to the market power of public transport providers, their procurement provisions can shape product portfolios of vehicle manufacturers, specifically for public service vehicles such as buses. Decisions to phase out diesel buses from public transport operations (i.e., to explicitly or implicitly exclude them from public tenders) were found in quite a few case studies: in Quito, diesel buses are no longer allowed in the Historic Centre and may not be procured after 2025; Madrid's public transport operator, EMT, announced to phase out diesel buses by the end of 2022 (while CNG powered buses and hybrid buses will remain in operation), and the Hamburg public transport authority phased out the procurement of diesel buses in 2020.

Provision of strategies and planning approaches (4): Most cities have formulated strategies and plans, highlighting new priorities for the mobility sector. We found that new priorities for urban mobility planning often were formulated in external, non-mobility strategies. This is not a surprise, as the transport sector is a major source of greenhouse gas emissions, urban air pollution, and land consumption, allowing for a strategic linkage of urban mobility with other policy areas, including environmental and health. Such policy integration questions traditional mobility planning approaches and objectives $[7,13,33]$. Hamburg's Climate Plan, for example, provides a "transition pathway" for the mobility transition, which includes measures to increase the modal share of public transport and active mobility (i.e., to reduce the share of car transport), or to phase out fossil fuel powered vehicles in public fleets; and European air quality legislation was the reason to implement access restrictions for diesel vehicles. In Madrid also, it was the Climate Action Plan that comprised the most comprehensive measures for the transformation of the urban mobility system. Pasig City's Comprehensive Land and Water Use Plan for 2015-2023 (CLWUP) and the accompanying Infrastructure and Utilities Development Plan embody the City's key objectives relating to the promotion of environmentally sustainable modes, improving the efficiency and inter-modality of urban public transportation, and the pursuit of transit-oriented development (TOD).

Especially cities in the Global South-including those covered in this study-are increasingly linking spatial and mobility planning around the TOD concept. TOD strategies aim at avoiding urban sprawl and developing compact, mixed-uses cities that reduce car dependency and to promote active mobility and transit riding instead [49,50] (p. 109). The 2013 Kigali Transport Master Plan planning until 2040 enshrined the concept of a "City of Green Transport" as one-and the "ultimate" one-of its six critical goals. This concept included the focus on TOD, public transport accessibility and the development of NMT infrastructure. In Dar es Salaam, the development of the city's BRT system is well announced in Dar es Salaam's 2008 and 2018 Urban Transport Master Plans as national commitment to mitigate transport sector emissions has shifted to the development of Mass Rapid Transport Systems [51,52]. Accompanying actions to consolidate the gains of the BRT system in Dar es Salaam have since been formulated to include the development of 
TOD strategies that recommend sustainable densities to creating a compact city, with mixed land uses complementing each other and identifying adequate spatial distribution of all land uses. In the case of Quito, the Development and Land Use Plan of Quito 2015-2025 (PMDOT) approved in 2015 is the master plan that leads all public policy development in the city, including some aspects of sustainable urban mobility. Moreover, supported by C40, in March 2021, the Municipality launched Quito's Climate Action Plan, in which one of the chapters is devoted to Sustainable Mobility, including (a) zero emissions PT, (b) zero emissions HCQ, (c) integrated and efficient PT, (d) active mobility [53]. Moreover, the Eco-Efficiency Tool, a municipal ordinance approved in 2017, aims to promote a compact city based on the concept of TOD, by generating a set of building parameters to contribute to dense and mixed-use development along the Bus Rapid Transit (BRT) and subway lines, where the use of private vehicles should be significantly reduced [54].

Regarding the provision and modification of standards and technical guidelines (5), Petzer et al. [36] found that the allocation of road space is often detailed in manuals and design guidelines [36] (p. 12). While such standards are normally issued the national level and focused on car-infrastructure, cities can adapt standards to local circumstances (ibid.). Hamburg, for example, introduced non-binding standards for the width of cycle paths that exceeded the minimum requirements set out in the national guidelines for the construction of urban roads [55] (p. 650). The City of Kigali is working on road design manuals on pedestrian-friendly street design, also to improve the attractivity of pedestrian amenities via trees and street furniture. Quito will launch (as of June 2021) standards for cycling infrastructure soon, which was elaborated with technical support from NACTO. In the Kathmandu valley, together with the initiation of bicycle lanes on car lanes, the Lalitpur Metropolitan City has formulated the Lalitpur Cycle Act 2020. It includes bicycle infrastructure development and implementation plans as well as user guidelines and rules.

Finally, we found that building regulations can be levers for cities to influence the urban mobility: In 2014, Hamburg abolished the obligation for developers to provide a minimum number of car parking spaces per newly built residential unit, stating in the official building codes that the accommodation of play areas for children as well as the provision of bicycle spaces on the property should have priority over the availability of parking spaces. Provisions on parking in building can also be found in transport planning documents. For instance, Kigali still has minimum parking standards in place but according to the 2020 Transport Master Plan, those "should be negotiable with developers in areas with good PT and NMT access" [48]. Moreover, in non-residential buildings, "the parking management system should seek to minimize car usage in commercial centers and avoid off-street parking facilities" [48]. Quito's Eco-Efficiency Tool (see above) sets standards for the provision of bicycle parking inside and outside new buildings and defines a maximum number of parking spaces per apartment [54].

\subsubsection{Exnovation Function 3: Change in the Allocation of Institutional and Material Resources}

The measures found for exnovation function 3 are summarized in Table 4 . Looking at the institutional changes (6), we found that half of the cities have introduced dedicated departments for mobility transition and/or formalized the representation of NMT stakeholders in political decision-making processes.

Reform of or creation of new departments to strengthen NMT: This ranges from creating new departments for non-motorized transport in Quito, to the creation of an independent Department for Transport and Mobility Transition in Hamburg, as "an expression of a special political priority" [56]. In Pasig, the establishment of the City Transport Development and Management Office (CTDMO) has accelerated the sustainability mobility agenda in the City and has complemented the initiatives of local government divisions that had traditionally been involved in ensuring safe and sustainable urban transportation services such as the City Environment and Natural Resources Office (CENRO), and the Traffic and Parking Management Office (TPMO). In the Kathmandu valley, a range of agencies is currently involved in the planning and development of transport systems and 
road infrastructure, but not in a cohesive manner. This situation hinders smooth planning and infrastructure development, despite the willingness of local authorities to support sustainable transport. Acknowledging this weakness, the government, under the Ministry of Physical Infrastructure and Transport, has issued a legal act in 2020, establishing the 'Kathmandu Valley Transport Authority' as the sole authority for steering and managing the development of the transport system.

Table 4. Results of the case studies-exnovation function E3 "Change in the allocation of institutional resources and urban space".

\begin{tabular}{|c|c|c|c|c|c|c|c|c|}
\hline & Ma & HH & Kig & $\mathrm{Ha}$ & Pas & Kat & Qui & Dar \\
\hline \multicolumn{9}{|c|}{ E3: Change in the Allocation of Institutional and Material Resources } \\
\hline \multicolumn{9}{|c|}{ Institutional changes (6) } \\
\hline $\begin{array}{l}\text { Reform or creation of departments to strengthen } \\
\text { NMT }\end{array}$ & $\mathrm{x}$ & $\mathrm{x}$ & & & $\mathrm{x}$ & $P$ & $\mathrm{x}$ & \\
\hline $\begin{array}{l}\text { Institutional uptake of niche-actors in the } \\
\text { administration }\end{array}$ & & & & & & $(\mathrm{x})$ & $\mathrm{x}$ & \\
\hline $\begin{array}{l}\text { New councils and forums to reflect non-car interests } \\
\text { and external (non-mobility) stakeholders }\end{array}$ & & $\mathrm{x}$ & & & $\mathrm{x}$ & & & \\
\hline \multicolumn{9}{|c|}{ Reallocation of material resources (7) } \\
\hline Pedestrianization & $\mathrm{x}$ & $\mathrm{x}$ & $\mathrm{x}$ & & $\mathrm{x}$ & $(\mathrm{x})$ & $\mathrm{x}$ & $\mathrm{x}$ \\
\hline $\begin{array}{c}\text { Permanent re-dedication of car-lanes or car parking } \\
\text { to PT incl. BRT or NMT }\end{array}$ & & & $(\mathrm{x})$ & & & & $x$ & $x$ \\
\hline (Temporary) bike lanes on main roads & $x$ & $\mathrm{x}$ & & & $x$ & & $\mathrm{x}$ & \\
\hline
\end{tabular}

Institutional uptake of niche-actors in the administration: We also found examples for the institutional uptake of activists and niche actors. In Quito, for example, the so called 'ciclopaseo', the closing $35 \mathrm{~km}$ of the main road every Sunday, which started as an initiative of cyclist groups in 2003, was institutionalized and the event is since then deeply enshrined in the administration, being responsible for its financing and coordination every Sunday. In Kathmandu, the Lalitpur Metropolitan City, together with the national Ministry of Physical Infrastructure and Transport, the United Nations Development Programme the Kantipur Media Group, and the Cycle City Network Nepal jointly launched a campaign to promote cycling and other environment-friendly practices in January 2021. The campaign focuses on advocacy and awareness for adoption of cycle-friendly policies and programs and environmentally sound lifestyle choices for urban populations [57].

New councils and forums to reflect non-car interests and external (non-mobility) stakeholders: Some cities created new institutions to institutionalize the exchange with new stakeholders and different administrative departments in order to integrate those non-car or even non-mobility perspectives into the policy process (Alliance for Cycling in Hamburg; City Transport Development and Management Office and Bicycling Promotion Committee in Pasig; or the Sustainable Mobility Modes Directorate in the Mobility Secretariat of the Municipality in Quito). In Pasig, the civil society (e.g., Partnership for Clean Air, Clean Air Asia), as well as informal networks (e.g., cycling groups in social media) has also played key roles in influencing cities, as well as national-level authorities in gearing towards more sustainable transportation pathways.

Beyond strengthening the political influence of non-car actors, the reallocation of material resources (7), which within the mobility system means reallocation of urban space, between mobility modes seems to be an important lever for urban mobility change. Petzer et al. argue that "close relationship between space and mobility systems sets it apart from other socio-technical systems that have been analyzed by transition scholars" [36]. 
Pedestrianization: In fact, we found that while most cities have started some activities related to pedestrianization or the redistribution of exclusive car space, efforts vary a lot in ambition and scope. Madrid and Quito pedestrianized larger parts of the city center (in Madrid this is a steady process over the past 10 years). In Kigali, a central avenue in the Central Business District (CBD) was pedestrianized in 2015, kicking-off the strategy of pedestrian corridors and zones enshrined in the 2013 Transport Master Plan. Other cities such as Kathmandu or Hamburg implemented smaller-scale interventions. Hamburg extended the existing pedestrian area by pedestrianizing a waterfront road along the Binnenalster, while in Kathmandu, a highly congested tourist hub named Thamel was made vehicle-free in 2017 [58]. In those cases, motivations were not primarily based on mobility-related considerations, but on increasing the attractiveness for tourists, or a higher quality of the inner city.

Permanent rededication of car-lanes or car parking to PT incl. BRT or NMT: Quito removed most on-street parking spaces in the historic center and introduced a $2 \mathrm{~h}$ limit for the remaining parking. In Dar es Salaam and Quito, several car lanes or on-street car parking spaces were turned into exclusive bus lanes when introducing the Bus Rapid Transport (BRT) system [59]. In Dar es Salaam also, the first phase of the BRT system has seen the construction of NMT infrastructure including pedestrian bridges and sidewalks especially near public transport stations and terminals as well as mobility management measures such as "Park and Ride system" system.

(Temporary) bike lanes on main roads: More recently, under the Covid-19 pandemic, many cities have turned car lanes into temporary cycle lanes on main roads. Several cities including Quito, Madrid, and Hamburg announced plans to make at least some of them permanent. The City of Pasig, through a local executive order issued during the height of the Covid-19 pandemic in 2020, has mobilized towards the identification and establishment of cycle lanes networks, as well as strategic interventions for improving pedestrian infrastructure in the city.

\subsubsection{Exnovation Function 4: De-Legitimizing Non-Sustainable Practices and Technologies}

Table 5 (below) summarizes the measures found in the city cases for exnovation function 4 .

Table 5. Results of the case studies-exnovation function E4 "De-legitimizing existing non-sustainable practices and technologies".

\begin{tabular}{|c|c|c|c|c|c|c|c|c|}
\hline & Мa & HH & Kig & На & Pas & Kat & Qui & Dar \\
\hline \multicolumn{9}{|c|}{ E4: De-Legitimizing Existing Non-Sustainable Practices and Technologies } \\
\hline \multicolumn{9}{|l|}{ Information and PR campaigns (8) } \\
\hline \multicolumn{9}{|l|}{ Experimentation (9) } \\
\hline Temporary conversion of car-space into public space & $(\mathrm{x})$ & & & & & & $\mathrm{x}$ & \\
\hline $\begin{array}{c}\text { Recurring car-free days/closing of streets for } \\
\text { motorized transport }\end{array}$ & & & $\mathrm{x}$ & $\mathrm{x}$ & $\mathrm{x}$ & $(\mathrm{x})$ & $\mathrm{x}$ & \\
\hline
\end{tabular}

[x = adopted/implemented $(\mathrm{x})=$ limited or small-scale implementation, $P=$ planned $].$

Information and PR campaigns (8): Social norms about "legitimate primary users of streets" and public space and transport infrastructure shape mobility behavior $[3,36,60]$. Driving and parking motorized vehicles is considered a normal use of public space, despite only a share of the urban population owning a personal motor vehicle, and despite the negative environmental and social impacts of motorized individual mobility. Although social norms are relatively stable, they can be altered, and they change over time. Still, we found no explicit attempts to delegitimize individual motorized transport like, e.g., communication or PR campaigns (those campaigns that we became aware of are rather proactive mobility and, thus, do not match the exnovation approach). In only rare cases have 
administrations chosen explicitly to announce the objective to reduce private motorized transport, like e.g., in Kigali, where the recent urban planning documents include an exnovation narrative, such as "keeping the private vehicle ownership on the low, and to avoid unsustainable, car-dependent, and sprawling settlement" [61].

Experimentation (9): Temporary and removable conversions of car-space into public space can be a means "for exploring systemic change in urban mobility, away from 'streets for traffic', and towards 'streets for people'" [62] and to questioning common "societal norms and beliefs about mobility and public space" allocation [60]. Experiments are a means to test and to visualize alternative uses of road space and potentially to convince citizens and stakeholders of the virtues of reduced car traffic — or to abandon such plans when acceptance remains low. Quito has introduced Urban Laboratories, in which socalled super-manzanas or super blocks, pedestrianization, etc., are tested. Moreover, it has launched a project of converting on-street parking into public spaces ("ParQuito" project).

Recurring car-free days/closing of streets for motorized transport: The installation of 'popup' on-street cycle lanes can be interpreted as public symbols for attempting to break the dominance of motorized vehicles even on main roads. Many of the above-mentioned temporary bicycle lanes are also planned to become permanent (see above, reported under E3). Other examples for experimentation are the bi-monthly Car-Free Days in Kigali, the yearly Car-free Days in Kathmandu (in 2014 and 2015), or the weekly Ciclopaseo in Quito, where motorized vehicles are not allowed on the streets to create space for alternative uses. In Hanoi, some streets in the old town quarters (around Hoan Kiem lake) are pedestrianized during weekends. Pasig has been implementing car-free Sundays in selected streets since 2012 .

\subsection{Exnovation Policies and Mobility System Elements}

In the following, we relate the findings on exnovation functions to the initially mentioned elements of the mobility system (as defined above: technologies and products; infrastructure and urban space allocation; planning practices; mobility habits, routines, and cost structures; formal and informal institutions; social norms and legal provisions). We draw first lessons on which system elements are being addressed on the urban level, identify policy gaps, on the interplay of local and national regulations.

We found that technologies and products are addressed in all our cases. Measures on the city level commonly target at replacing combustion vehicles. While cities lack the legal power to regulate market access for and technical characteristics of new vehicles (e.g., via emission standards), they can regulate the use of vehicles within their territory. Related measures include access restrictions for combustion vehicles to city centers or street segments, the ban of combustion vehicles from being used for mobility services; or public procurement strategies that exclude the purchase of diesel buses for public transport operators. The scope of national level activities is more nuanced: it ranges from incremental improvements of combustion vehicles via emission standards or CO2-based fuel taxation, to more profound exnovation measures, like prohibiting the registration or the import of used fossil fueled vehicles. In some of our case studies, especially where our case is the main city of the country and seat of the national government, the distinction between city and national level is blurred: In Kathmandu, for example, the ban of diesel three-wheelers was a decision of the national government, and, accordingly, there is no entry under E1.

The adaptation of infrastructures and the distribution of public space are core competencies of local level decision-making. Accordingly, measures to re-allocate public space among the transport modes are relatively widespread in our case cities (again, keep in mind that we did not assess the level of ambition, but the diffusion among the cities). This includes the removal of on-street parking, the pedestrianization of road space, or the conversion of car lanes into bus or cycle lanes.

Mobility behavior and routines are addressed from the exnovation perspective through measures that aim at making unsustainable transport less attractive, such as for example, increasing the costs of private motorized vehicle use. Still, combustion vehicles are commonly 
considered as the most convenient, safest, and often also cheapest way of getting around in the city. We found that overall costs of owning motor vehicles are mostly determined on the national level via registration fees, vehicle taxes, or import taxes. Local authorities can strongly influence the costs of motor vehicle use in the city area (beyond fuel taxation, which again is determined on the national level). Parking management is a widespread tool; while further options such as congestion charges or employer contributions based on the number of parking spaces provided for employees are the exception and none of our cities has implemented such schemes.

Apart from the financial side, city governments and planners can make private car use less convenient by limiting vehicle access to city areas, reducing the availability of parking spaces, or imposing odd-even regulations that prohibit the use of a private car every other day. While most of our case studies have implemented some kind of such measures, reallocating (or even planning to re-allocate) physical infrastructure is very prone to political conflict-as was clearly demonstrated by the rollback and redesign of Madrid Central (the LEZ in Madrid's city center). This also explains why cycling infrastructure is often an add-on to car lanes (commonly at the expense of pedestrian space) rather than a diversion of urban space from motor vehicle infrastructure.

While there will be institutions relevant to each city at the national level and international level, cities can certainly set their own agendas within the urban institutional structure. Mobility-related decision making processes often are biased through the strong political influence of pro-car stakeholder groups such as car owners' associations, compared to the organized interests of active modes and alternative mobility e.g., [32]. Experience from the Civitas SUMPs-Up project has also indicated that local shop owners and business associations tend to be very skeptical of restricting car accessibility to the city center, fearing that this would scare away customers. The creation of new institutions in the urban mobility context, we found, can potentially increase the relative influence of non-car stakeholders on political decisions, be it the creation of multi-stakeholder alliances for sustainable mobility in Hamburg or Pasig, or the reframing or creation of government departments (in Quito, Pasig, and Hamburg).

Moreover, our observations suggest that the most fundamental exnovation measures originate from outside the 'traditional' mobility policy area, i.e., from environmental and climate policies (and potentially also social and industry-strategic considerations). The integration of non-mobility policies on the city, the national, and the European level seem to be a powerful driving force behind exnovation measures, as the example of Hamburg's Climate Plan and the influence of European air quality legislation has shown.

A key lever for cities, changing existing planning practices is surprisingly only being applied rather timidly. In a long-term perspective, institutional fragmentation between mobility and spatial planning can lead to urban sprawl with poor public transport coverage, resulting in increased car-dependence [63] (p. 57). We found strategies for linking spatial and mobility planning around the Transit Oriented Development (TOD) concept in Kigali, Quito, and Dar es Salaam. Still, no city explicitly attempted to change fundamental planning paradigms such as the predict-and-provide approach or street planning from 'inside' to 'outside', that focus on meeting the demands of motorized traffic [3] (p. 6). This might be explained through the tacit nature (i.e., the lack of codification) and the embeddedness of such paradigms in scientific disciplines, which makes them hard to address on the city level.

Social norms and the social appreciation of car use compared to cycling, walking, and public transport seem to be powerful elements to perpetuate a "culture of vehicle ownership" [64] (p. 135): Social norms involve intersubjectively shared beliefs and standards of 'appropriate' behavior [65] (p. 891), for example that public transport or active mobility are transport means for poor people who cannot afford to own a car [3] (p. 7); that owning a car is a symbol of social status; or that on-street car parking is considered a 'normal' use of scarce urban space. Such norms are often codified in legal provisions and regulations for the use of public space $[36,60]$. We found that no city openly challenges the 
idea that private motorized vehicles are the normal—or even desirable—way of moving through cities. Same as the above-mentioned planning paradigms, social norms are hard to address directly. More indirectly, however, city governments can implement experiments to demonstrate how urban space could be used alternatively, such as temporary pedestrianization, road closures, or urban laboratories-which we found in some cities-are ways for administrations to communicate what else could be considered an appropriate urban mobility and space use, though in a very cautious way. Based on these findings, the following table (Table 6) provides the specified exnovation framework for urban mobility transitions. It shows and details Kivima and Kern's exnovation functions by providing levers and more concrete examples for local level interventions.

Table 6. Adapted and detailed framework for urban mobility exnovations.

\begin{tabular}{|c|c|c|c|}
\hline & $\mathbf{X}$ & $(\mathrm{x})$ & $P$ \\
\hline \multicolumn{4}{|l|}{ E1: Bans on unsustainable technologies and practices } \\
\hline \multicolumn{4}{|l|}{ Regulation (1) } \\
\hline Circulation bans/access restrictions based on vehicle characteristics & 3 & 3 & 1 \\
\hline Ban/regulation of mobility services based on vehicle characteristics & & 2 & \\
\hline Inner-city speed limits, going beyond nationally defined standard & 3 & & \\
\hline \multicolumn{4}{|l|}{ E2: Significant changes in regime rules } \\
\hline \multicolumn{4}{|l|}{ Financial mechanism (2) } \\
\hline Pricing of on-street parking & 6 & & \\
\hline \multicolumn{4}{|l|}{ Public procurement (3) } \\
\hline Exclusion of diesel public transport vehicles from public tenders & 3 & & \\
\hline \multicolumn{4}{|l|}{ Provision of strategies and planning approaches (4) } \\
\hline City strategies and plans highlighting changed policy priorities for urban mobility & 6 & 1 & \\
\hline Standards for urban planning (TOD, compact, mixed use, etc.) & 4 & & \\
\hline \multicolumn{4}{|c|}{ Provision and revision of standards and technical, guidelines and manuals (5) } \\
\hline Quality standards for bike lanes & 3 & 2 & 1 \\
\hline Building regulations (ending provisions of car parking) & 2 & 2 & \\
\hline \multicolumn{4}{|l|}{ E3: Change in the allocation of institutional and material resources } \\
\hline \multicolumn{4}{|l|}{ Institutional changes (6) } \\
\hline Reform of or creation of new departments to strengthen NMT & 4 & & 1 \\
\hline Institutional uptake of niche-actors in the administration & 1 & 1 & \\
\hline New councils and forums to reflect non-car interests and external (non-mobility) stakeholders & 2 & & \\
\hline \multicolumn{4}{|l|}{ Reallocation of material resources (7) } \\
\hline Pedestrianization & 7 & 1 & \\
\hline Permanent re-dedication of car-lanes or car parking to PT including BRT or NMT & 2 & 1 & \\
\hline (Temporary) bike lanes on main roads & 4 & & \\
\hline \multicolumn{4}{|c|}{ E4: De-legitimizing existing non-sustainable practices and technologies } \\
\hline Information and PR campaign (8) & 0 & & \\
\hline \multicolumn{4}{|l|}{ Experimentation (9) } \\
\hline Temporary conversion of car-space into public space & 1 & 1 & \\
\hline Recurring car-free days/closing of streets for motorized transport & 4 & 1 & \\
\hline
\end{tabular}

[The four exnovation functions are highlighted in grey (E1-E4); the broader categories of instruments/measures are written in bold (1-9); the specifications for the mobility system based on the city cases' findings are listed in italic].

We conclude that none of our cities applies a systemic approach, targeting all system elements with exnovation measures. In our understanding, applying a comprehensive strategic transition approach would imply that supporting innovations and the more 
sustainable alternatives goes hand in hand with consciously ending unsustainable system elements. We do believe that this perspective could help to highlight the need to consciously target all system elements with exnovation measures. The different exnovation functions and corresponding policy instruments can serve as a 'toolbox' for selecting those measures that best fit the context.

\section{Conclusions: Policy Recommendations and Future Research}

In this section, we discuss the limitations of our approach, draw conclusions, and formulate policy recommendations as well as further research questions.

At this stage of research, we looked at rather progressive cities, which aim at altering their urban mobility systems through innovations, covering a broad spectrum of world regions. Our task was to compile an overview of exnovation measures and to understand how the exnovation approach can be further detailed for better understanding urban mobility systems. Our research started from a generic framework, based on Kivima and Kern and other sources, compiled quantitative empirical data from a set of city case studies, and linked both in a more detailed exnovation framework for sustainable urban mobility systems.

To further specify the exnovation perspective on urban mobility systems, and to make the exnovation approach useful for studying mobility transformations, we conducted a quantitative assessment ('counting') of measures in the city case studies. This approach misses the 'completeness' of policy responses, i.e., the design and interaction of measure packages, as well as the level of ambition, or the impact on modal shares and the emission of greenhouse gases. We also counted measures that are only announced or at the planning stage, knowing that measures might not be passed or implemented in the same way as announced. There might be conflicts arising over the implementation or changes in government, which lead to changing or withdrawing certain measures. We found such examples in our research, e.g., the already mentioned LEZ in Madrid, which was partly withdrawn (at least stripped of the ambitious exnovation elements) after the change of government took place.

Being aware of this, we are planning to further develop and expand this research in qualitative in-depth assessments of the cities in subsequent articles by diving deeper into the individual cases - and hopefully also inspire other researchers to follow us on this path. Aspects that should be considered in such studies comprise:

- The interplay of the different governance levels, including questions such as: for which elements of the mobility regime are national level activities a precondition for cities to act (e.g., the implementation of a low emission zone might require a national level emission category scheme for vehicles)? For which system elements can cities even lead exnovation processes? We found interesting examples for multilevel implications, such as the 2021 Spanish Climate Change Law, which made LEZs mandatory for cities over 20.000 inhabitants-and which led eight municipios in the southern parts of Madrid to sign an agreement, even before the law was enacted.

- Drivers of exnovation pressures: this is well connected to the question above, but also goes beyond: While national and regional legislation certainly plays an important role, it would be insightful to better understand the role of knowledge networks, local change agents, and civil society pressure. In-depth case studies tracking the exnovation processes could provide insights. This is in line with Kungl and Geels 2021, highlighting the need to further understand the role of policymakers in regime destabilization.

- Power struggles and discourses around exnovation measures: We found evidence that exnovation measures are harder to implement than innovation measures since they tend to face stronger political resistance. Future research should aim at better understanding the discourses and power struggles around exnovation measures, but also ways that city administrations found to overcome initial resistance. This includes an analysis of anxieties and reservations of city officers against ambitious exnovation 
measures. In this regard, an assessment of cases that are considered a success, such as the re-election of Paris' mayor even after banning traffic from inner city areas, can provide valuable insights. Other cities have used experiments-temporary and removable interventions such as pedestrian areas - to test and increase the acceptance of policy measures. A systematic assessment of such tools and approaches to enhance the acceptance of exnovation measures and to weaken the resistance of powerful stakeholder groups could support progressive local administrations.

- $\quad$ Patterns or sequence of exnovation processes: Further research could help substantiate what-drawing from the insights of our case studies-so far can be formulated as hypothesis only: that there is a typical pattern or sequence of exnovation processes, e.g., first targeting technologies, and only at a later stage infrastructure, institutions, and mobility behavior.

- In-depth case studies should also investigate whether cities strategically link innovation and exnovation policies. This comprises the strategic linkage of fostering innovative solutions on the one hand, while pushing back 'old' technologies, norms, and behaviors on the other hand. This includes the re-purposing of urban space, which has been identified as a key factor when modeling future transport systems.

We hope that this exnovation framework can enrich and facilitate a more complete and strategic assessment of urban mobility transformation processes-both for researchers and political decision-makers.

Despite our purely quantitative approach, our findings allow for drawing some policy recommendations:

Based on our case studies and referring to the exnovation functions, we suggest city authorities should pay more attention to institutional settings and consciously engage actors to counterbalance the existing influence structures. We found examples such as multi-stakeholder alliances to enhance NMT, the creation of dedicated positions and departments to integrate niche activists, or the reframing of the competences of administrative departments. We assume that strategic issue linkage between mobility, environmental, climate, health, and economic policies can be a strong driver for ending unsustainable practices and phasing out outdated technologies.

Exnovation as outlined in this paper can make a considerable contribution to shape innovation towards solutions that take a wider societal perspective and foster mobility as a service rather than mobility as a product. This is particularly relevant for rightsizing vehicles, where fiscal and regulatory exnovation (E1, E2, and E3) measures can help steering innovation towards more energy- and resource-efficient vehicle concepts. Similarly, exnovation measures explored in this paper can help prioritizing more efficient modes and services and with that foster innovative solutions for example for shared and public transport solutions.

Moreover, the exnovation function E4, de-legitimizing of the unsustainable system elements, also seems to be important, because it touches upon values and behavior. We are aware that influencing social norms is politically delicate and hard to stir in a top-down manner. Still, progressive cities could promote narratives containing positive images of NMT through experimentation within all elements of the system (e.g., the temporary pedestrianization of streets, conversion of on-street-parking to public spaces) as a way forward, making the benefits of phasing-out 'the old' tangible-this way delegitimizing the unsustainable, yet dominant alternative. Especially in cities where resources are limited, it would be important to exemplify and exchange experiences on how this can be done with low-cost measures (infrastructure is expensive-but making neighborhoods more livable should also be started with temporary means. De-legitimizing could also comprise bans of advertisement of motorized vehicles on public space.

We also recommend not only to focus on the city center, but on the entire city. Though of course interventions in the city center hold symbolic importance, e.g., Madrid Central, the same symbolic importance accounts for difficulties and resistance and hamper political support and public acceptance. Changing this approach and starting in peripheral neigh- 
borhoods, where interventions might be more appreciated, can be a better starting point, which was shown by the Belo Horizonte case, where the successful Zone 30 implementation before schools spilled over to other parts of the city, allowing even intervention in the city center.

The good practices and successful examples of exnovation measures should be distributed and shared via city networks. For many of our case study cities, those networks have proven to be important drivers in changing the political discourse and local priorities (particularly Pasig, Quito). Moreover, bilateral partnerships, such as cities-to-cities partnerships or local universities with universities in cities with high shares of NMT/PT (the latter can be considered an important driver in Kigali) can be helpful.

Last, though it might sometimes seem as if innovation and exnovation measures are not clearly distinguishable, we recommend using this perspective and our definition for thinking about the transformation of the (urban) mobility system. It can help sharpen measures and pave the way towards a more sustainable mobility system. This entails thinking about each element of the mobility system ('systemic approach') and applying the exnovation functions to each of them. While, e.g., building bicycle infrastructure can be considered a measure supporting more sustainable urban mobility, the exnovation perspective contributes that this infrastructure could and should be rededicated from car lanes (in order to 'end' unsustainable practices). It should be clearly stated that applying the exnovation perspective does not suggest forgetting about innovation; as the title suggests: it should be the other side of the policy coin. Ideally, there is a clear link between innovation and exnovation measures (e.g., banning access for private combustion cars, while strategically supporting e-bikes and electrified public transport as a viable alternative).

Author Contributions: Conceptualization \& Methodology, L.G. and S.W.; Case Study Data and Interviews, E.M. [Kigali], A.M. [Pasig], M.R.M.B. [Quito], H.T.T.N. [Hanoi], E.T. [Dar es Salaam], S.S. [Kathmandu], L.G. [Madrid], S.W. [Hamburg]; Writing—Original Draft Preparation and Review \& Editing, L.G. and S.W.; Supervision, funding acquisition, O.L. All authors have read and agreed to the published version of the manuscript.

Funding: Research that led to the publication of this paper has been supported by the European Union's Horizon 2020 Framework Programme, Grant Agreement No. 875041 (SOLUTIONSplus), 101006598 (FUTURE HORIZON) and the Urban Pathways project (BMU International Climate Initiative 17_I_357_Global_M_Urban Pathways).

Institutional Review Board Statement: The study was conducted according to the H2020 ethics standards and approved by the SOLUTIONSplus consortium (January 2020).

Informed Consent Statement: Informed consent was obtained from all subjects involved in the study.

Data Availability Statement: The data presented in this study are available on request from the corresponding authors. The data are not publicly available due to confidentiality agreement with the interviewees included in this study.

Acknowledgments: We would like to thank all members and partners of the Urban Change Maker Group based at TU Berlin and all interviewees who agreed to share their knowledge and take part in this study.

Conflicts of Interest: The authors declare no conflict of interest.

\section{References}

1. Urry, J. The 'System' of Automobility. Theory Cult. Soc. 2004, 21, 25-39. [CrossRef]

2. Vigar, G. Local "Barriers" to Environmentally Sustainable Transport Planning. Local Environ. 2000, 5, 19-32. [CrossRef]

3. Agarwal, O.P.; Kumar, A.; Zimmerman, S. Emerging Paradigms in Urban Mobility: Planning, Financing and Management; Elsevier: Amsterdam, The Netherlands; Cambridge, MA, USA, 2019, ISBN 978-0-12-811434-6.

4. Geels, F.W. Technological Transitions as Evolutionary Reconfiguration Processes: A Multi-Level Perspective and a Case-Study. Res. Policy 2002, 31, 1257-1274. [CrossRef]

5. Geels, F.W. The Multi-Level Perspective on Sustainability Transitions: Responses to Seven Criticisms. Environ. Innov. Soc. Transit. 2011, 1, 24-40. [CrossRef] 
6. Von Stechow, C.; McCollum, D.; Riahi, K.; Minx, J.C.; Kriegler, E.; van Vuuren, D.P.; Jewell, J.; Robledo-Abad, C.; Hertwich, E.; Tavoni, M.; et al. Integrating Global Climate Change Mitigation Goals with Other Sustainability Objectives: A Synthesis. Annu. Rev. Environ. Resour. 2015, 40,363-394. [CrossRef]

7. Lah, O. Sustainable Development Synergies and Their Ability to Create Coalitions for Low-Carbon Transport Measures. Transp. Res. Procedia 2017, 25, 5083-5093. [CrossRef]

8. Kern, K. Cities as Leaders in EU Multilevel Climate Governance: Embedded Upscaling of Local Experiments in Europe. Environ. Politics 2019, 28, 125-145. [CrossRef]

9. Geels, F.W. Technological Transitions and System Innovations. A Co-Evolutionary and Socio-Technical Analysis; Edward Elgar Publishing Ltd.: Cheltenham, UK, 2005.

10. Grin, J.; Rotmans, J.; Schot, J. Transitions to Sustainable Development; Routledge: Oxfordshire, UK, 2010, ISBN 978-0-203-85659-8.

11. Mattioli, G.; Roberts, C.; Steinberger, J.K.; Brown, A. The Political Economy of Car Dependence: A Systems of Provision Approach. Energy Res. Soc. Sci. 2020, 66, 101486. [CrossRef]

12. Kungl, G.; Geels, F.W. Sequence and Alignment of External Pressures in Industry Destabilisation: Understanding the Downfall of Incumbent Utilities in the German Energy Transition (1998-2015). Environ. Innov. Soc. Transit. 2018, 26, 78-100. [CrossRef]

13. Sims, R.; Schaeffer, R.; Creutzig, F.; Cruz-Núñez, X.; D’Agosto, M. Transport. In Climate Change 2014: Mitigation of Climate Change; Contribution of Working Group III to the Fifth Assessment Report of the Intergovernmental Panel on Climate Change; Intergovernmental Panel on Climate Change: Geneva, Switzerland, 2014.

14. Yin, R. Changing Urban Bureaucracies: How New Practices Become Routinized. The Rand Corporation; Lexington Books: Santa Monica, DC, USA, 1979.

15. Kimberly, J.R. Mangerial Innovation. In Handbook of Organizational Design; Nystrom, P.C., Starbuck, W.H., Eds.; Oxford University Press: Oxford, UK, 1981; pp. 84-104.

16. Rodriguez, H.P.; Henke, R.M.; Bibi, S.; Ramsay, P.P.; Shortell, S.M. The Exnovation of Chronic Care Management Processes by Physician Organizations. Milbank Q. 2016, 94, 626-653. [CrossRef]

17. Bynum, J.; Passow, H.; Carmichael, D.; Skinner, J. Exnovation of Low Value Care: A Decade of Prostate-Specific Antigen Screening Practices. J. Am. Geriatr. Soc. 2019, 67, 29-36. [CrossRef]

18. Geels, F.W. Regime Resistance against Low-Carbon Transitions: Introducing Politics and Power into the Multi-Level Perspective. Theory Cult. Soc. 2014, 31, 21-40. [CrossRef]

19. Turnheim, B.; Geels, F.W. Regime Destabilisation as the Flipside of Energy Transitions: Lessons from the History of the British Coal Industry (1913-1997). Energy Policy 2012, 50, 35-49. [CrossRef]

20. Arnold, A.; David, M.; Hanke, G.; Sonnenberger, M. Innovation-Exnovation. Über Prozesse des Abschaffens und Erneuerns in der Nachhaltigkeitstransformation; Ökologie und Wirtschaftsforschung: Berlin, Germany, 2015; Volume 99.

21. David, M. Moving beyond the Heuristic of Creative Destruction: Targeting Exnovation with Policy Mixes for Energy Transitions. Energy Res. Soc. Sci. 2017, 33, 138-146. [CrossRef]

22. Heyen, D.A. Governance of Exnovation: Phasing out Non-Sustainable Structures; Working Paper 2/2017; Öko-Institut eV: Freiburg, Germany, 2017.

23. Heyen, D.A.; Hermwille, L.; Wehnert, T. Out of the Comfort Zone! Governing the Exnovation of Unsustainable Technologies and Practices. Gaia Ecol. Perspect. Sci. Soc. 2017, 46, 326-331. [CrossRef]

24. Davidson, D.J. Exnovating for a Renewable Energy Transition. Nat. Energy 2019, 4, 254-256. [CrossRef]

25. Kivimaa, P.; Kern, F. Creative Destruction or Mere Niche Support? Innovation Policy Mixes for Sustainability Transitions. Res. Policy 2016, 45, 205-217. [CrossRef]

26. Smith, A.; Raven, R. What Is Protective Space? Reconsidering Niches in Transitions to Sustainability. Res. Policy 2012, 41, 1025-1036. [CrossRef]

27. Moezzi, M.; Janda, K.B.; Rotmann, S. Using Stories, Narratives, and Storytelling in Energy and Climate Change Research. Energy Res. Soc. Sci. 2017, 31, 1-10. [CrossRef]

28. Howarth, C. Informing Decision Making on Climate Change and Low Carbon Futures: Framing Narratives around the United Kingdom's Fifth Carbon Budget. Energy Res. Soc. Sci. 2017, 31, 295-302. [CrossRef]

29. Janda, K.B.; Topouzi, M. Telling Tales: Using Stories to Remake Energy Policy. Build. Res. Inf. 2015, 43, 516-533. [CrossRef]

30. David, M.; Gross, M. Futurizing Politics and the Sustainability of Real-World Experiments: What Role for Innovation and Exnovation in the German Energy Transition? Sustain. Sci. 2019, 14, 991-1000. [CrossRef]

31. OECD. Communicating Environmentally Sustainable Transport: The Role of Soft Measures; OECD: Paris, France, 2004, ISBN 978-92-64-10663-5.

32. Geels, F.W. A Socio-Technical Analysis of Low-Carbon Transitions: Introducing the Multi-Level Perspective into Transport Studies. J. Transp. Geogr. 2012, 24, 471-482. [CrossRef]

33. Werland, S. Diffusing Sustainable Urban Mobility Planning in the EU. Sustainability 2020, 12, 8436. [CrossRef]

34. Moradi, A.; Vagnoni, E. A Multi-Level Perspective Analysis of Urban Mobility System Dynamics: What Are the Future Transition Pathways? Technol. Forecast. Soc. Chang. 2018, 126, 231-243. [CrossRef]

35. Sheller, M. Mobility Justice: The Politics of Movement in the Age of Extremes; Verso: London, UK; Brooklyn, NY, USA, 2018, ISBN 978-1-78873-092-1. 
36. Petzer, B.J.M.; Wieczorek, A.J.; Verbong, G.P.J. The Legal Street: A Scarcity Approach to Urban Open Space in Mobility Transitions. Urban Transform. 2021, 3, 3. [CrossRef]

37. Hodson, M.; Geels, F.; McMeekin, A. The UK Mobility System. Deliverable D2.3: 'Integrated Analysis of D2.1 and D2.2 to Assess the Feasibility of Different Transition Pathways'. Available online: https:/ /openarchivaris.nl/blob/98/b2/1dd95c6126132746338 7c8bf3122.pdf (accessed on 11 June 2021).

38. Ananchev, G. Embodying the Regime of Automobility: A Phenomenology of the Driving Subject and the Affects of Governable Space. Ph.D. Thesis, The University of Wisconsin-Milwaukee, Milwaukee, WI, USA, 2016.

39. Turoń, K.; Kubik, A.; Chen, F.; Wang, H.; Łazarz, B. A Holistic Approach to Electric Shared Mobility Systems DevelopmentModelling and Optimization Aspects. Energies 2020, 13, 5810. [CrossRef]

40. Turoń, K.; Kubik, A.; Chen, F. Electric Shared Mobility Services during the Pandemic: Modeling Aspects of Transportation. Energies 2021, 14, 2622. [CrossRef]

41. Bishop, T.; Barber, C.; Charman, S.; Porter, G. Enhancing Understanding on Safe Motorcycle and Three-Wheeler Use for Rural Transport. Available online: https://assets.publishing.service.gov.uk/media/5e18aadeed915d3b10b9c48e/BishopetalAmendTransaid-2017-EnhancingUnderstandingMotorcyclesThreeWheelers-LiteratureReview-AfCAP-RAF2114A-180319.pdf (accessed on 11 June 2021).

42. Wachter, C.; Schüttoff, M.; Rinderknecht, F.; Goletz, M.; Ehebrecht, D.; Lenz, B.; Kühnel, M.; Hanke, B. Electric Three-Wheelers as an Alternative to Combustion-Engined Autorickshaws in Dar Es Salaam-Generation of a Standard Drive Cycle, Power Train Modelling and Simulation of the Energy Demand of Light Electric Vehicles. In Proceedings of the 2020 Fifteenth International Conference on Ecological Vehicles and Renewable Energies (EVER), Monte-Carlo, Monaco, 10-12 September 2020.

43. Dar es Salaam City Council Motorcycle Permits-Important Attachments When Applying for a Permit to Enter/Park in the Center of CBD City) for Two/Tricycles. Available online: http:/ / dcc.go.tz/vibali-vya-pikipiki (accessed on 11 June 2021).

44. Bhattarai, A. When Kathmandu Was 'Shangri-La for Electric Vehicles'. Bloomberg CityLab. Available online: https://www. bloomberg.com/news/articles/2019-08-26/why-nepal-once-led-the-world-in-electric-buses (accessed on 3 June 2021).

45. Kojima, M.; Brandon, C.; Shah, J. Improving Urban Air Quality in South Asia by Reducing Emissions from Two-Stroke Engine Vehicle; World Bank: Washington, DC, USA, 2000.

46. Halvorson, B. Nepal Was Once an Electric-Vehicle Leader. What Happened? 2019. Available online: https: / / www.greencarreports. com/news/1125158_nepal-was-once-an-electric-vehicle-leader-what-happened (accessed on 2 June 2021).

47. Ayuntamiento de Madrid. Ordenanza de Movilidad Sostenible; Boletín Oficial de la Comunidad de Madrid (BOCM-20181023-36); City Council of Madrid: Madrid, Spain, 2018.

48. City of Kigali. Final Transport Report. Kigali Master Plan 2050; Kigali, Rwanda. 2020. Available online: https:/ /bpmis.gov.rw / asset_uplds/kigali_master_plan/3_Kigali\%20Master\%20Plan_Transport\%20PlanLowRes.pdf (accessed on 4 May 2021).

49. World Bank. Dar Es Salaam Metropolitan Development Project-Benchmarking Transit Oriented Development; World Bank: Washington, DC, USA, 2018.

50. Cervero, R.; Guerra, E.; Al, S. Beyond Mobility; Island Press/Center for Resource Economics: Washington, DC, USA, 2017, ISBN 978-1-61091-928-9.

51. Dar es Salaam City Council. Dar Es Salaam Transport Policy and System Development Master Plan, 2008; Dar es Salaam City Council: Dar es Salaam, Tanzania, 2008.

52. Dar es Salaam City Council. The Project for Revision of Dar Es Salaam Urban Transport Master Plan; Dar es Salaam City Council: Dar es Salaam, Tanzania, 2018.

53. Secretaría de Ambiente Plan de Acción de Cambio Climático de Quito (PACQ 2020), Municipio del Distrito Metropolitano de Quito (MDMQ), Quito, Ecuador. 2020. Available online: https://www.quitoneutral.com/pacq2020 (accessed on 4 May 2021).

54. STHV Herramienta Eco-Eficiencia. Available online: http://sthv.quito.gob.ec/portfolio/eco-eficiencia2/\# (accessed on 9 June 2021).

55. Clausen, S.; Buch, T.; Wilma, U.; Kopplin, D. Die ReStra Oder: Neue Regelwerke Hat Das Land (Hamburg)! Straßenverkehrstechnik 2018, 62, 646-653.

56. Bürgerschaft der Freien und Hansestadt Hamburg. Drucksache 22/564. Neustrukturierung Der Behörden 2020; Bürgerschaft der Freien und Hansestadt Hamburg: Hamburg, Germany, 2020.

57. UNDP. Campaign to Promote Cycling for Healthy Cities Launched; UNDP: New York, NY, USA, 2021.

58. Himalayan News Service. Thamel Declared No-Go Zone for Vehicles; The Himalayan Times: Anamnagar, Kathmandu, 2017.

59. Mchomvu, Y.E. The Dar Es Salaam Bus Rapid Transit (BRT) System; Presentation a the SSATP Annual General Meeting Abuja, Nigeria. Available online: https://www.ssatp.org/sites/ssatp/files/publication/yonas_mchomvu_wb.pdf (accessed on 31 May 2021).

60. Prytherch, D. Law, Engineering, and the American Right-of-Way; Springer International Publishing: Cham, Switzerland, 2018, ISBN 978-3-319-75704-9.

61. City of Kigali. Kigali City Zoning Regulations. Kigali Master Plan 2050; Kigali, Rwanda. 2020. Available online: https: / / masterplan2020.kigalicity.gov.rw/portal/sharing/rest/content/items/b9e31b07d8684053b0f3eac8649e1213/data (accessed on 4 May 2021).

62. Bertolini, L. From "Streets for Traffic" to "Streets for People": Can Street Experiments Transform Urban Mobility? Transp. Rev. 2020, 40, 734-753. [CrossRef] 
63. Crozet, Y.; Santos, G.; Coldefy, J. Shared Mobility, MaaS and the Regulatory Challenges of Urban Mobility; Centre on Regulation in Europe (CERRE): Brussels, Belgium, 2019.

64. Government of Spain. Spain Integrated National Energy and Climate Plan 2021-2030; European Commission: Brussels, Belgium, 2020.

65. Finnemore, M.; Sikkink, K. International Norm Dynamics and Political Change. Int. Organ. 1998, 52, 887-917. [CrossRef] 